\title{
A Smart Anti-theft System for Vehicle Security
}

\author{
Pritpal Singh, Tanjot Sethi, Bibhuti Bhusan Biswal, and Sujit Kumar Pattanayak
}

\begin{abstract}
Security, especially theft security of vehicle in common parking places has become a matter of concern. An efficient automotive security system is implemented for anti-theft using an embedded system integrated with Global Positioning System (GPS) and Global System for Mobile Communication (GSM).This proposed work is an attempt to design and develop a smart anti-theft system that uses GPS and GSM system to prevent theft and to determine the exact location of vehicle. The system contains GPS module, GSM modem, Infrared sensors, DTMF decoder IC MT8870DE, 8051 microcontroller, relay switch, vibration sensor, paint spray and high voltage mesh. GPS system track the current location of vehicle, there are two types of tracking used one is online tracking and other is offline tracking. GSM system is also installed in the vehicle for sending the information to the owner of the vehicle because GPS system can only receive the vehicle location information from satellites. In case of accident this system automatically sends the message for help to ones relatives. The preventive measures like engine ignition cutoff, fuel supply cutoff, electric shock system (installed on steering wheel) and paint spray system are installed in the vehicle which is controlled using user or owner GSM mobile. The owner can lock or unlock his/her vehicle with the help of SMS. This complete system is designed taking in consideration the low range vehicles to provide them extreme security.
\end{abstract}

Index Terms-Global positioning system (GPS), global system for mobile communications (GSM), microcontroller 8051, tracking.

\section{INTRODUCTION}

These day's vehicle robbery cases are higher than any other time, it has gotten to be fundamental to give a vehicle a superb security with the main solid hostile to burglary gadget. Vehicle focal locking framework guarantees the best ensure to secure your vehicle from various types of burglary cases. It is a vehicle security gadget that offers fantastic insurance to your vehicle. However this framework couldn't demonstrate to give complete security and openness to the vehicle in the event of burglary. So a more created framework makes utilization of an inserted framework focused around GSM innovation. The outlined and created framework is introduced in the vehicle. Whether one is holder of single vehicle or in excess of 1000, Vehicle Tracking System (VTS) is an answer for spot, track and secure your portable resources. It is intended for exact and ongoing following and reporting of your vehicle(s), regardless of where it is placed.

Manuscript received February 2, 2015; revised April 24, 2015.

Pritpal Singh, Tanjot Sethi, and Bibhuti Bhushan Biswal are with the Industrial Design from National Institute of Technology, Rourkela, Odisha, India (e-mail: pritpa1332@gmail.com, tanjotsinghsethi@gmail.com, bbbiswal@ nitrkl.ac.in).

Sujit Kumar Pattanayak is with the Department of Mechanical Engineering, National Institute of Technology Silchar, Assam, India (e-mail: sujupat@gmail.com).
Combination of high-affectability GPS units in vehicle following frameworks has empowered these gadgets to work in different varieties of situations, for example, characteristic ravines, urban gulches and much under substantial foliage, the length of system scope is solid. Right now GPS vehicle following guarantees their wellbeing as voyaging. This vehicle following framework found in clients vehicles as a burglary counteractive action and salvage gadget. Vehicle manager or Police take after the sign emitted by the following framework to place a victimized vehicle in parallel the stolen vehicle motor rate going to diminished and pushed to off. In the wake of exchanging on the motor, engine can't restart without consent of watchword. This framework introduced for the four wheelers, Vehicle following generally utilized as a part of naval force administrators for war fleet administration capacities, directing, send off, ready for and security. The applications incorporate observing driving execution of a guardian with a teenager driver. Vehicle following frameworks acknowledged in shopper vehicles as a burglary avoidance and recovery gadget. In the event that the burglary recognized, the framework sends the SMS to the vehicle holder. After that vehicle manager sends the SMS to GSM modem appended to the controller, issue the important signs to stop the robbery.

The principle point of the present exploration work is to outline and create a shrewd and strong security framework for vehicles that can avert robbery and give data on mischances. The framework being produced through the present work utilizes GPS and GSM innovation and can be made moderate so it can be utilized as a part of ease vehicles even in bikes.

\section{A BRIEF REVIEW}

In many previous research works, the authors have given some analytical view of the circuit used in the various projects, while in some other global positioning system (GPS) is commonly used as global navigation satellite system is used to locate the vehicles and also to stop the vehicle if stolen. The location information is sent in the form of message containing latitude, longitude and speed information to the owner of the vehicle or location can also be traced using internet through Google maps.

A number of developments have taken place in anti-theft systems for vehicles and some of the relevant ones are as follows.

The utilization of ARM 7 microcontroller, GSM and GPS module together with an accelerometer and temperature sensor is carried out by Joshi and Mahajan [1]. The GPS and GSM module is being utilized for following the area of vehicle. The extra part is being included is the accelerometer which essentially contains the MEMS sensor offering a low 
pass filter and is fundamentally utilized for Shake Detection, Orientation Detection and Tap Detection. The utilization of temperature sensor is additionally being carried out with a specific end goal to acquire the vehicle engine temperature which changes over the estimation of temperature into electrical signal.

A hybrid GPS-GSM localization of vehicles Tracking System has been developed by Al-Khedher [2] that portrays an incorporated GPS-GSM framework to track vehicles utilizing Google Earth application. The remote module has a GPS mounted on the moving vehicle to recognize its present position, and to be exchanged by GSM with different parameters procured by the car's information port as a SMS to a beneficiary station. The received GPS directions or coordinates are sifted utilizing a Kalman filter to upgrade the precision of measured position. After information processing, Google Earth application is utilized to view the current area and status of every vehicle. This objective of this framework is to oversee armada, police cars dissemination and auto burglary alerts.

A security system based on RFID, GPS and GSM [3] consolidate the establishment of an electronic gadget in a vehicle, with reason planned machine programming to empower the organization to track the vehicle's area. At the point when the car pics the worker; he/she needs to swap the RFID card. The micro controller matches the RFID card no. with its database records and sends the representative's id, taxi id \& the taxicab position co-ordinates to the organization unit by means of GSM module. The GSM Modem will get the message through GSM in the organization unit. On the off chance that worker ends up/herself in an issue, he/she will press the catch. Microcontroller will distinguish the activity and sends a signal to the GSM which will arrange with to the organization unit and police.

The configuration and advancement of a burglary control framework for an automobile, which is being utilized to anticipate/control the robbery of a vehicle has been accounted for by Wankhade and Dahad [4]. The created framework makes utilization of an implanted framework focused around Global System for Mobile correspondence (GSM) engineering. The planned and created framework is introduced in the vehicle. An interfacing portable is additionally associated with the microcontroller, which is thusly, joined with the engine. Once, the vehicle is being stolen, the data is being utilized by the vehicle manager for further handling. The data is passed onto the focal handling protection framework which is as the sms, the microcontroller unit peruses the sms and sends it to the Global Positioning System (GPS) module and utilizing the triangulation system, GPS module sustains the precise area as scope and longitude to the client's versatile.

Shaikh et al. [5] describe arm7 based smart car security system. The principle point of this undertaking is to offer a development security framework in automobile, which comprises of a face detection subsystem, a GPS module, a GSM module and a control stage. The face location subsystem can discover confronts in vehicle amid the period in which no one ought to be in the auto, and make an alert uproariously or soundlessly. Alternate modules transmit vital data to clients and help to keep eyes on vehicle constantly, actually when the vehicle is lost. This framework model is based on the base of one inserted stage Arm7 which controls all the processes.

Jian-ming et al. [6] describe vehicles against robbery framework utilizing GSM and GPS module. The framework is created utilizing fast blended sort single-chip C8051f120 and stolen vehicle is discovered by the utilization of vibration sensor. The framework stays in contact with auto holder through the GSM module, for the safety and reliability of car.

Kaushik et al. [7] depicts an Anti-burglary vehicle security framework which plans to permit access to the vehicle just if the individual's finger impression matches with that put away in the framework. The correlation will happen in Matlab and result will be demonstrated on the LCD. On the off chance that through illicit means the vehicle is accessed then vehicle fuel tank will be bolted through Relay circuit so that at whatever point the tank gets unfilled, unapproved individual will never again have the capacity to refuel the tank.

Ibrahim et al. [8] describe a hostile to burglary security framework that uses an installed framework outline with Dual Tone Multi Frequency (DTMF) and a GSM to screen and shield an automobile. It secures the auto or vehicle against burglary. Upon actuation, it naturally grounds the auto by detaching the ignition scratch supply from the auto battery. In an attempt of theft through the car doors or boot, the system sends text message to the car owner and at the same time starts up an alarm.

Nagaraja et al. [9] describe the outline and improvement of a GSM based vehicle robbery control framework for a car. The created framework makes utilization of an inserted framework focused around GSM innovation. An interfacing mobile or GSM modem is associated with the microcontroller, which in term is joined with the engine through relay. In the event that the vehicle is stolen, the data is sent to the owner that somebody has stolen his vehicle. After that the user or owner will send the message to GSM modem or mobile which is joined with motor ignition through transfer or relay to switch off the engine.

Rashed et al. [10] describe a GPS based tracking system that keeps track of the location of a vehicle and its speed based on a mobile phone text messaging system. The system is able to provide real-time text alerts for speed and location. The present location can be locked and the system will alert the owner if the vehicle is moved from its present locked location. In every one hour the GSM modem or mobile will inform the owner by messaging its location in the form of latitude, longitude and speed information. The owner or user can control or stop the vehicle by simply sending the message stop to GSM modem or mobile connected to circuitry board. After receiving that message ignition system will turn off.

\section{HARDWARE DESCRIPTION}

\section{A. GSM Model}

A smart anti-theft vehicle security system (Fig. 1) consist of GSM module, GPS module, 8051 microcontroller, infrared sensors, DTMF decoder IC MT8870DE, relay, paint spray and high voltage mesh. The hardware design is split into two parts- GSM and GPS. The main circuit is divided into two circuits one is for detecting the motion of thief using 
infrared sensors and other is for DTMF tone decoding for switching on/off the relay. The bock diagram (Fig. 2), when thief tries to unlock the car, the infrared sensors placed near the car door will sense the motion or movement and will sent the signal to 8051 microcontroller. The microcontroller which is connected to triggering circuit will send the triggering signal to relay. The relay is connected to GSM mobile through earphone. The microcontroller will send triggering signal three times to GSM mobile and call will be made to user informing him or her that someone is trying to unlock the vehicle.

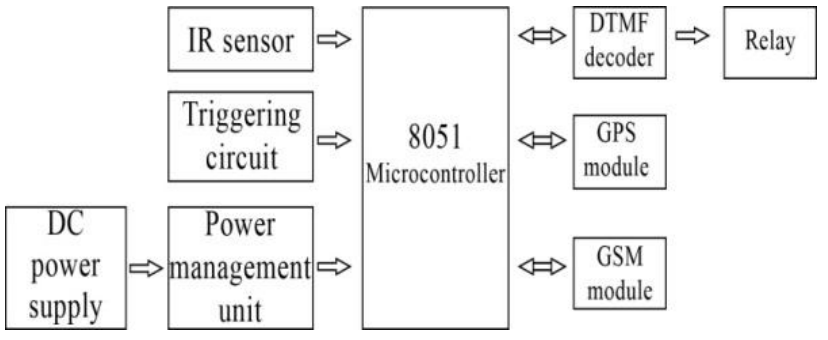

Fig. 1. Anti-theft system architecture.

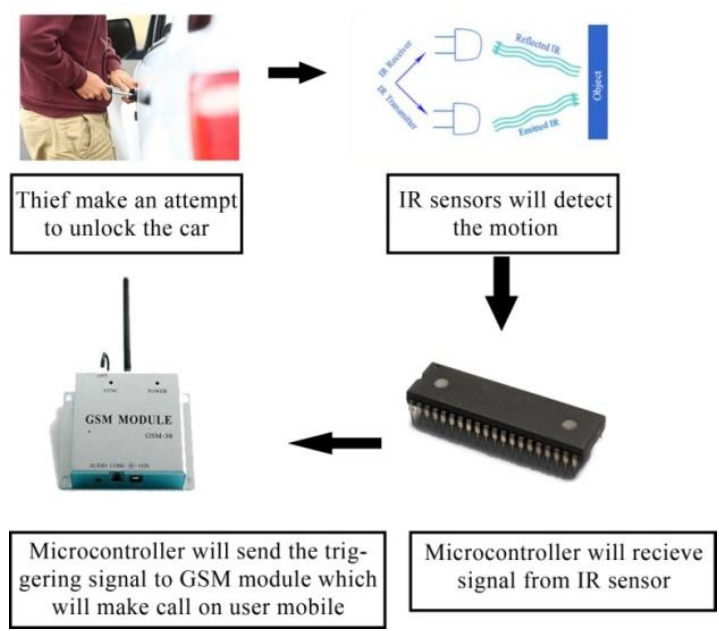

Fig. 2. Block diagram for detecting thief movement.

The second part is for controlling or switching different systems like engine ignition, fuel supply, electric shock mesh and windscreen paint spray using relay. The relay is controlled using GSM mobile and DTMF tone decoder.

DTMF tone detection and decoding is provided by IC MT8870DE.This circuit detects the dial tone from a telephone line and decodes the keypad pressed on the remote telephone. The dial tone we heard when we pick up the phone set is call Dual Tone Multi-Frequency, DTMF in short. The name was given because the tone that we heard over the phone is actually making up of two distinct frequency tones, hence the name dual tone. The DTMF tone is a form of one way communication between the dialer and the telephone exchange. A complete communication consists of the tone generator and the tone decoder. Here we are use the IC MT8870DE, the main component to decode the input dial tone to 5 digital outputs. These digital bits can be interface to a computer or microcontroller for further application.

There is particular range of frequency (Fig. 3) for each keypad number which will be decoded by DTMF decoder circuit. Depending upon the system like ignition cut-off, fuel supply cut-off, windscreen paint spray and electric shock mesh, the number of relays controlling them will be added. There are four relays in the circuit each one of them controlling the preventive system like engine ignition cut-off. The owner will send the DTMF tone to the GSM mobile placed in the car. The DTMF tone will be decoded using IC MT8870DE which will be controlling relays to activate security system. For example number 1 on the mobile keypad is assigned for engine ignition cut-off, on pressing 1 number on the keypad of your mobile phone, the DTMF decoder will decode the keypad tone frequency and microcontroller will switch the relay on-off depending upon the program burn in the microcontroller.

\begin{tabular}{|c|c|c|c|c|}
\hline 1 & 2 & 3 & A & $697 \mathrm{~Hz}$ \\
\hline 4 & 5 & 6 & B & $770 \mathrm{~Hz}$ \\
\hline 7 & 8 & 9 & C & $850 \mathrm{~Hz}$ \\
\hline$*$ & 0 & $\#$ & D & $941 \mathrm{~Hz}$ \\
\hline $1209 \mathrm{~Hz}$ & $1336 \mathrm{~Hz}$ & $1477 \mathrm{~Hz}$ & $1633 \mathrm{~Hz}$ & \\
\hline
\end{tabular}

Fig. 3. DTMF keypad frequencies.

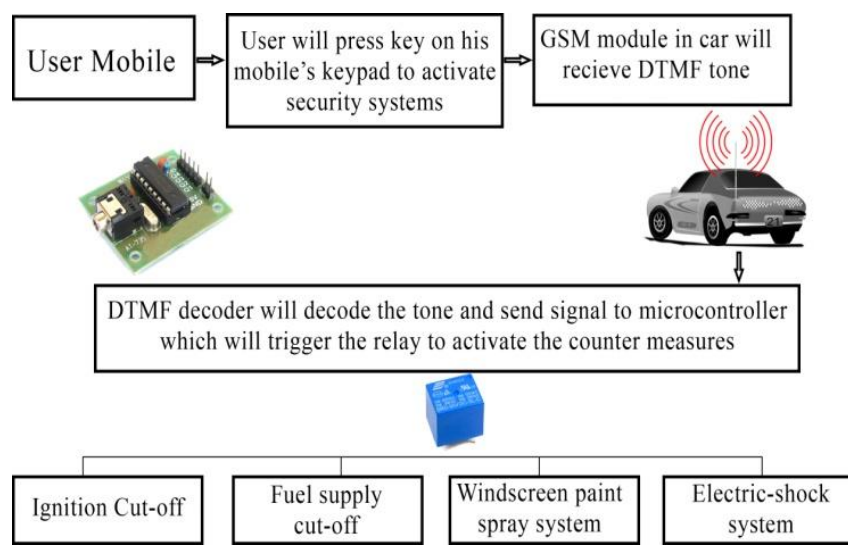

Fig. 4. Block diagram for switching different systems using DTMF decoder circuit using relay.

The mechanism of security system is presented through a block diagram in Fig. 4. Whenever someone attempts to unlock the vehicle, the security components installed in the vehicle sends a signal to the owner of the vehicle via GSM modem or GSM mobile. The owner then tries to establish connectivity with the security system in the vehicle through calling a predefined number. Once the connectivity is established, the owner can choose one of the four actions like engine ignition cut-off, fuel supply cut-off, windscreen paint system and electric shock system as per his judgment in order to prevent the vehicle from theft. Each keypad number is assigned for controlling different system. On pressing 1 from user mobile engine ignition will cut-off, on pressing 2 fuel supply system will cut-off, on pressing 3 electric shock system provided on steering wheel will get activated which 
will give shock to thief and on pressing 4 windscreen paint spray system gets activated so that thief can't drive the vehicle.

The complete working model comprises of GPS and GSM system as shown in Fig. 5. Fig. 6 shows the complete circuit layout for decoding DTMF tone through which relays are controlled that further controls the preventive systems like engine ignition cut-off, fuel supply cut-off, windscreen paint spray system and electric shock system.

The circuit diagram for detecting the motion of thief is shown in Fig. 7. The main components used in the circuit are microcontroller 8051 and infrared sensors.

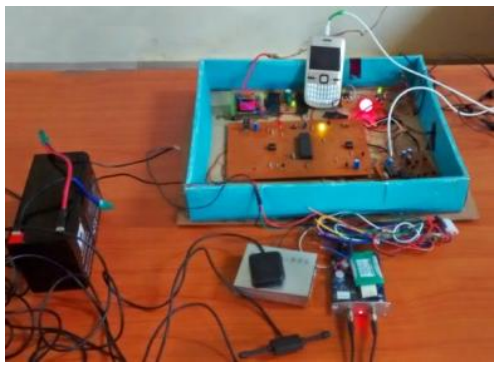

Fig. 5. GPS and GSM system for vehicle.

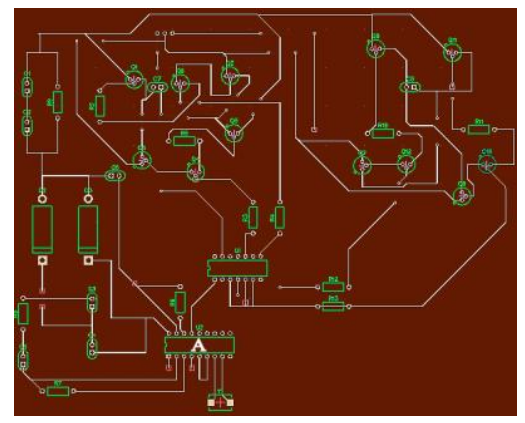

Fig. 6. DTMF tone decoding circuit layout using dip trace A (DTMF decoder IC MT8870DE).

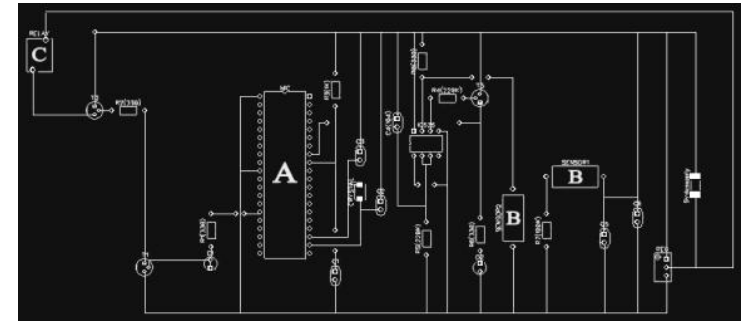

Fig. 7. Circuit diagram for sensing motion and triggering GSM mobile A (8051 Microcontroller), B (IR Sensor) \& C (Relay).

\section{B. GPS Model}

The Global Positioning System (GPS) is a space-based satellite route framework that gives area and time data in all climate conditions, anyplace on or close to the Earth where there is an unhampered observable pathway to four or more GPS satellites. The framework gives basic abilities to military, common and business clients as far and wide as possible. It is kept up by the United States government and is uninhibitedly open to anybody with a GPS receiver.

A GPS receiver (Fig. 8) calculates its position by precisely timing the signals sent by GPS satellites high above the Earth. Each satellite continually transmits messages that include: the time the message was transmitted and satellite position at time of message transmission. The receiver uses the messages it receives to determine the transit time of each message and computes the distance to each satellite using the speed of light. Each of these distances and satellites' locations define a sphere. The receiver is on the surface of each of these spheres when the distances and the satellites locations are correct. These distances and satellites locations are used to compute the location of the receiver using the navigation equations. This location is then displayed, perhaps with a moving map display or latitude and longitude; elevation information may be included. Many GPS units show derived information such as direction and speed, calculated from position changes. In typical GPS operation, four or more satellites must be visible to obtain an accurate result.

A GPS tracking unit is a device that uses the Global Positioning System to determine the precise location of a vehicle, person, or other asset to which it is attached and to record the position of the asset at regular intervals. The recorded location data can be stored within the tracking unit, or it may be transmitted to a central location data base, or to internet connected pc, using a cellular (GPRS or SMS), radio, or satellite modem embedded in the unit. This allows the asset's location to be displayed against a map backdrop either in real time or when analyzing the track later, using GPS tracking software.

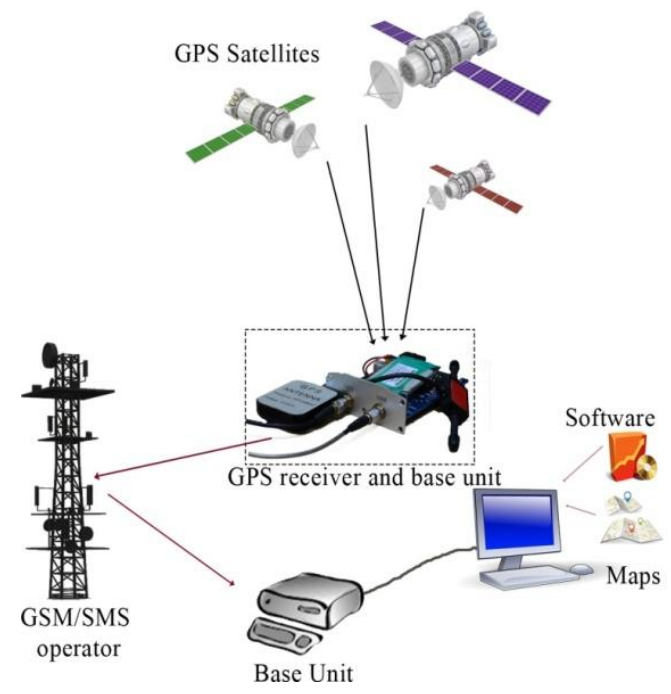

Fig. 8. Block diagram of GPS tracking system.

The complete specification of GPS receiver used in the system is shown in the Table I.

TABLE I: SPECIFICATION OF GPS SYSTEM

\begin{tabular}{ll}
\hline \hline CONTENT & SPECIFICATIONS \\
\hline Dimension & $83^{*} 54^{*} 26 \mathrm{~mm}$ \\
Weight & $120 \mathrm{~g}$ \\
Band & $850 / 900 / 1800 / 1900 \mathrm{Mhz}$ \\
Network & GSM/GPRS \\
GSM/GPRS Module & SIM900B \\
GPS Module & SIRF3 chip \\
GPS Sensitivity & $-159 \mathrm{dBm}$ \\
GPS Accuracy & $5 \mathrm{~m}$ \\
Voltage of car power system & $12 \mathrm{~V}-24 \mathrm{~V}$ \\
Backup battery & $3.7 \mathrm{~V} 800 \mathrm{mAh} \mathrm{Li-ion} \mathrm{battery}$ \\
Storage Temp & $-40^{\circ} \mathrm{C}$ to $+85^{\circ} \mathrm{C}$ \\
Operation Temp & $-20^{\circ} \mathrm{C}$ to $+65^{\circ} \mathrm{C}$ \\
Humidity & $5 \%--95 \%$ non-condensing \\
\hline \hline
\end{tabular}




\section{RESUlTS AND DisCUSSION}

The online based tracking framework is a framework planned by joining of a few present day data and communication technologies. The framework comprises of vehicle-mounted following gadgets, a focal server framework and web based application. Through the framework, clients will have the facility of observing the area graphically and other important data of vehicle. This framework is intended to serve undertakings with a boundless number of vehicles and complex utilization prerequisites. The online framework empowers client to scan area track on guide through created web application install Google Map and interface with database server for vehicles track subtle elements. Utilizing the online based framework empowers clients with diverse working framework stages to effectively achieve the requested subtle elements by the presence of web access. Fig. 9 demonstrates an outline of a common online based vehicle tracking framework. The area is acquisitioned from satellite utilizing GPS receiver area coordination sent through GPRS, the GSM system will pass the data to the objective server as HTTP packets. Also through the web the customers can peruse track on electronic guide utilizing reason composed web application on site. The client can discover the way of the terminus or complete course with headings (Fig. 10) where he need to experience web application.

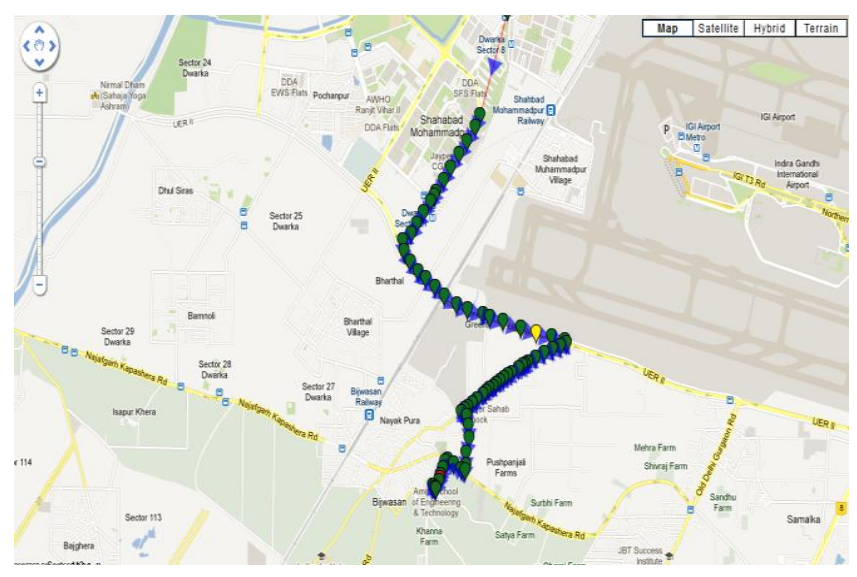

Fig. 9. Online tracking system using web application.

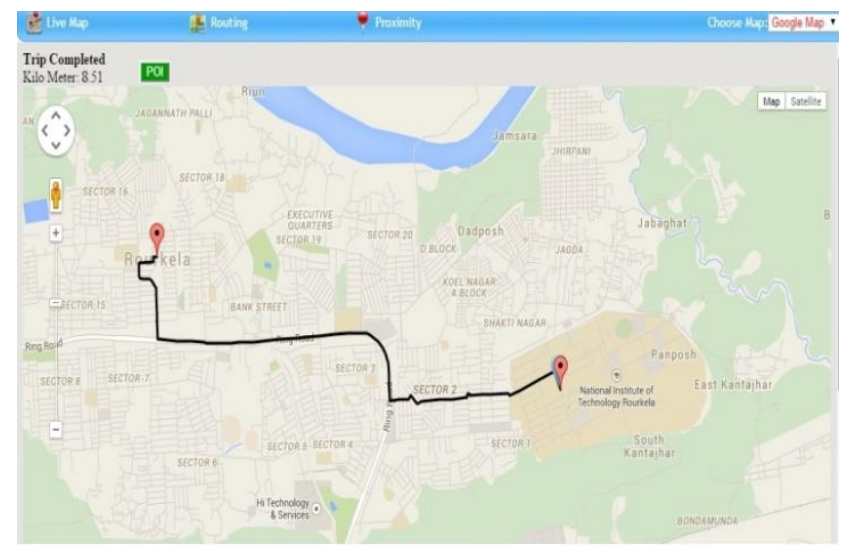

Fig. 10. Online finding the direction or destination.

Fig. 11. shows trip or history replay of vehicle on entering or selecting date and time when the journey or trip was made. Through web application (Fig. 12) the client can likewise produce history report of the vehicle. The history report of vehicle comprises of separation secured, vehicle status (ignition on/off), fuel status, velocity report, temperature report and $\mathrm{AC}$ on/off report.

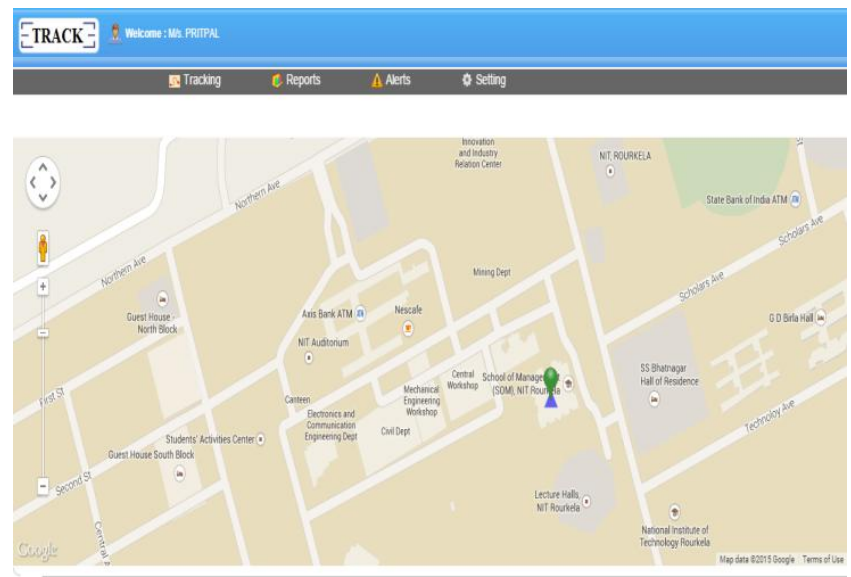

Fig. 11. History replay of vehicle.

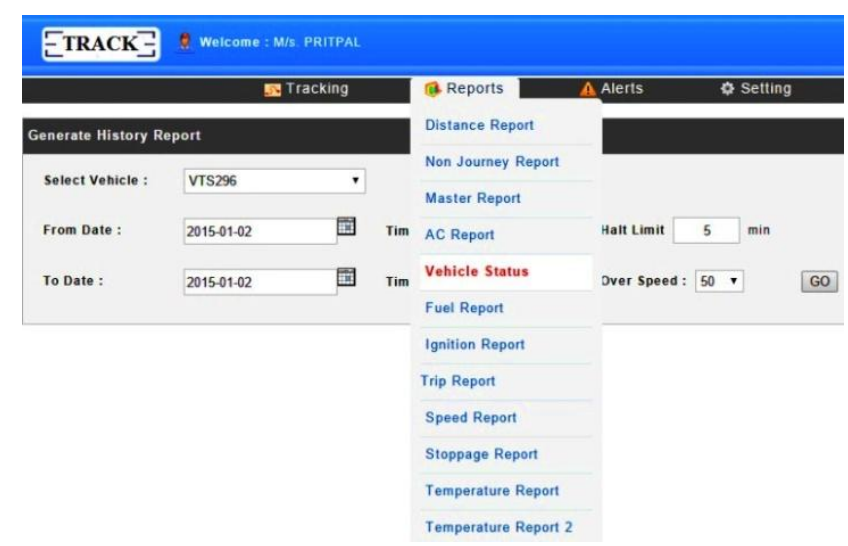

Fig. 12. Generate history report of vehicle.
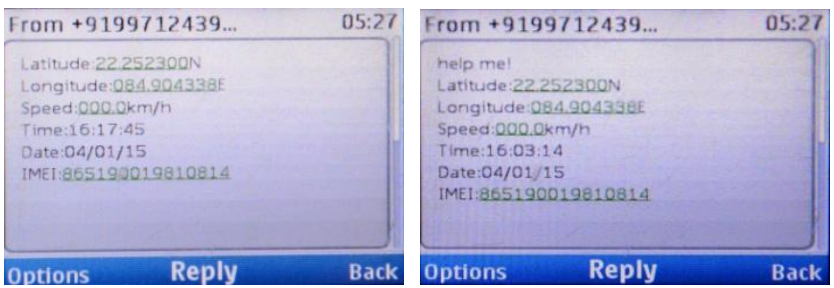

Fig. 13. Offline tracking using GSM. Fig. 14. MSG sent in case of accident to one of the family member.

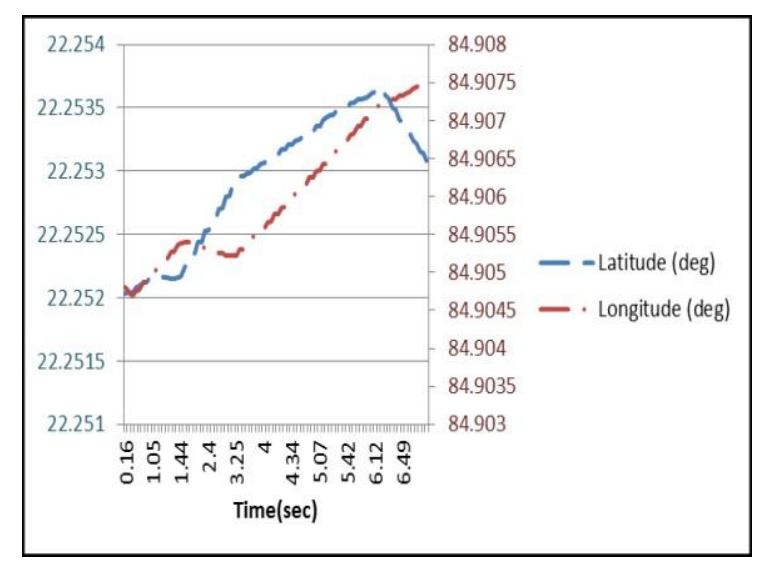

Fig. 15. Experimental result.

In offline tracking Fig. 13, GPS receiver after receiving the 
signal from satellites calculates the position of vehicle and convert it in the form of latitude, longitude, altitude and speed information. This information is send to the user by GSM modem or mobile phone connected to circuitry board. In case of accident (Fig. 14), GSM modem or mobile will send the help message to one of the family member whose number is registered. The Experiment (Fig. 15) was conducted for checking the sensitivity of GPS tracking system.

\section{CONCLUSION}

Tracking framework or system is getting to be progressively vital in expansive urban areas and it is more secured than different frameworks. It has continuous ability, rises with a specific end goal to fortify the relations among individuals, vehicle and street by assembling present day data advances or technologies and ready to structures a real time accurate, compelling exhaustive transportation framework. Updating this setup is simple which makes it open to future a prerequisite which likewise makes it more efficient. The proposed work is cost-effective, reliable and has the function of preventing theft and providing accurate tracking system. A smart anti-theft system is one of the essential systems that homogenize both GPS and GSM systems. It is fundamental because of the huge numbers of uses of both GSM and GPS frameworks and the wide use of them by a great many individuals all through the world. This framework intended for clients in area development and transport business, provides real-time information such as location, speed and expected arrival time of the user is moving vehicles in a concise and easy-to-read format. This framework might likewise valuable for correspondence process among the two focuses.

\section{REFERENCES}

[1] M. S. Joshi and D. V. Mahajan, “Arm 7 based theft control, accident detection and vehicle positioning system," International Journal of Innovative Technology and Exploring Engineering, vol. 4, no. 2, pp. 29-31, July 2014.

[2] M. A. A. Khedher, "Hybrid GPS-GSM localization of automobile tracking system," International Journal of Computer Science and Information Technology, vol. 3, no. 6, pp. 75-85, Dec 2011.

[3] S. S. Pethakar, N. Srivastava, and S. D. Suryawanshi, "RFID, GPS and GSM based vehicle tracing and employee security system," International Journal of Advanced Research in Computer Science and Electronics Engineering, vol. 1, no. 10, pp. 91-96, Dec. 2012.

[4] P. P. Wankhade and S. O. Dahad, "Real time vehicle locking and tracking system using GSM and GPS technology-an anti-theft system," International Journal of Technology and Engineering System, vol. 2, no. 3, pp. 272-275, March 2011.

[5] J. R. Shaikh and S. M. Kate, "Arm7 based smart car security system," International Journal of Engineering Trends and Technology, vol. 3, no. 2, pp. 210-212, March 2012.
[6] J. M. Hu, J. Li, and G. H. Li, "Automobile anti-theft system based on GSM and GPS module," presented at the Fifth International Conference on Intelligent Networks and Intelligent Systems, Tianjin, China, November 1-3, 2012.

[7] N. Kaushik, M. Veralkar, P. Parab, and K. Nadkarny, "Anti-Theft vehicle security system," International Journal for Scientific Research and Development, vol. 1, no. 12, pp. 2845-2848, March 2014.

[8] V. M. Ibrahim and A. A. Victor, "Microcontroller based anti-theft security system using GSM networks with text message as feedback," International Journal of Engineering Research and Development, vol. 2, no. 10, pp. 18-22, Aug 2012.

[9] B. G. Nagaraja, R. Rayappa, M. Mahesh, C. M. Patil, and T. C. Manjunath, "Design and development of a GSM based vehicle theft control system," presented at the International Conference on Advanced Computer Control, Singapore, January 22-24, 2009.

[10] M. A. A. Rashed, O. A. Oumar, and D. Singh, "A real time GSM/GPS based tracking system based on GSM mobile phone," IEEE Journal on Signals and Telecommunication, vol. 3, no. 1, pp. 65-68, March 2014.

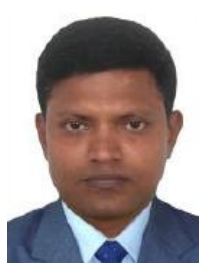

Pritpal Singh is pursuing his master of engineering in industrial design from National Institute of Technology, Rourkela. He has completed his B.Tech. in instrumentation and control engineering from Guru Gobind Singh Indraprastha University, Delhi. Presently he is working on aerial robotics and embedded systems.

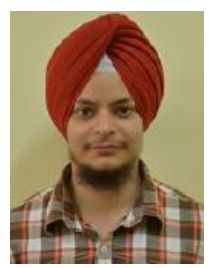

Tanjot Sethi is pursuing his master of engineering in industrial design from National Institute of Technology, Rourkela. He has completed his B.Tech. mechanical engineering from Baba Banda Singh Bahadur Engineering College, Punjab. Presently he is working on industrial robotics and control.

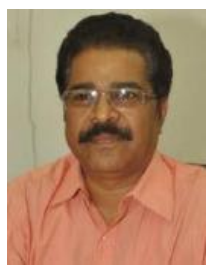

Bibhuti Bhushan Biswal graduated in mechanica enginnering from UCE, Burla, India in 1985. Subsequently he completed his M.Tech, and Ph.D. from Jadavpur University, Kolkata. He joined the faculty of mechanical engineering at UCE Burla from 1986 and continued till 2004 and then joined National Institute of Technology, Rourkela as professor and currently he is the professor and head of Department of Industria Design. He has been actively involved in various research projects and published more than 100 papers at National and International levels. His areas of research interest include industrial robotics, FMS, computer integrated manufacturing, automation, and maintenance engineering. He was a visiting professor at MSTU, Moscow and a visiting scientist at GIST, South Korea.

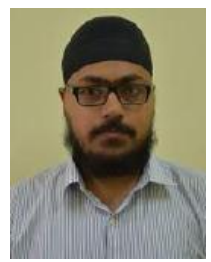

Sujit Kumar Pattanayak graduated in mechanical enginnering from UCE, Burla, India in 1996 Subsequently he completed his M.Tech from UCE, Burla, India in 2003. He served as a faculty of mechanical engineering at diffengineering colleges from 1996 to 2005 and then joined National Institute of Technology Silchar, Assam, India as assistant professor in Department of Mechanical Engineering. Presently he is pursuing his $\mathrm{Ph}$. D. at NIT silchar. 